\title{
NCAA Academic Performance Program (APP): Future Directions
}

\author{
Walter Harrison \\ University of Hartford
}

\begin{abstract}
This paper represents the first major effort to conduct a comprehensive review of the National Collegiate Athletic Association (NCAA) Academic Performance Program (APP) and to recommend to the NCAA Board of Directors those modifications that will lead to further improvement in graduation performance. They fall into four categories: (a) new initial eligibility standards; (b) new requirements for 2-year college transfers; (c) new requirements for eligibility for postseason competition; and (d) new penalty structure and penalty thresholds. Conclusions and recommendations are offered.
\end{abstract}

Please indulge me if I open with a few personal observations from the perspective of someone who has served on the National Collegiate Athletics Association (NCAA) Board of Directors and who has been the only chair of the NCAA Committee on Academic Performance (CAP). As a member of the Board, I saw the graduation data that caused that group to seek a systematic approach that would produce better outcomes. I was a part of those discussions that sought improvement without denying access to college- and university-level education for individuals, especially ethnic minorities, who were capable of working at that level while also participating in intercollegiate athletics. Then in my role with CAP, I observed and coordinated the work to design, implement, and refine a system that would work across the diverse membership of the NCAA's Division I. A number of principles have undergirded this work from the beginning. CAP achieves a number of objectives: (a) ensures that student-athletes have real academic opportunities; (b) mandates that colleges are living up to their academic obligations to student-athletes; (c) makes decisions with the goal of improving academic success - not punishing students and schools; (d) bases all decisions on the best data available, and if CAP does not have data, it attempts to acquire data that would support better policies; and (e) continues to monitor its data to track intended and unintended consequences of its decisions, as this remains a work in progress.

I feel confident in saying that the members of CAP have embraced these principles over the years. The system is the best that we have been able to achieve to this point, but we remain committed to addressing any opportunities for improvement.

Harrison is President, University of Hartford, Hartford, CT, and Chair, Committee on Academic Performance, NCAA. 
In many respects, this Keynote within the 2012 NCAA Scholarly Colloquium is a report on the first major effort to conduct a comprehensive review of the NCAA Academic Performance Program (APP) and to recommend to the NCAA Board of Directors those modifications that will lead to further improvement in graduation performance, while continuing to adhere to the principles stated previously.

The most recent efforts for academic reform within the NCAA were initiated in a mandate from the organization's Board of Directors and have been designed and implemented through a committee, CAP, with important support from the NCAA staff. Following the Board mandate, initial design of the APP took place. This was followed by implementation, including initial data reporting and experience. Finally, we have had a chance to review the results and make modifications for the future. I will review each of these stages in this paper. This first cycle of the new academic reform effort has produced some significant progress, as well as some lessons and insights, all of which formed the basis for a review of the APP and led to recommendations recently adopted by the NCAA Board of Directors.

\section{Mandate for Academic Reform and Foundations for a System}

As an example of one part of the history of academic reform, in a meeting of the NCAA Board of Directors in April 2000, the Board considered establishing an incentive-based financial aid model in which overall financial aid limits in the sport of Division I men's basketball would be based on each institution's average 4-year graduation rate. At the time, the graduation rate in question would have been what is called the Federal Graduation Rate (FGR). This rate will be discussed later in this paper, along with issues that make using this rate as the basis for what would essentially be a penalty system that would have reduced the number of permissible grants-in-aid for squads with low graduation rates.

Subsequently, a more comprehensive approach to academic reform was adopted that was driven by a mandate from the NCAA Board that can be paraphrased as follows: create a system that will produce improved graduation performance, particularly in specific high-profile sports, without having disparate impact on ethnic minorities. The sports of primary concern initially were football and men's basketball. The concern for disparate impact on ethnic minorities mirrored a running conversation within the NCAA regarding the consequences for ethnic minorities of relying on test scores to determine qualifications for athletic grants-in-aid.

Two special purpose committees formed within the NCAA conducted the analysis and proposals that became the foundation for the APP. One was a group called Academic Consultants, and the second was called the Incentives and Disincentives Workgroup. The system that emerged from this work has three major parts, each of which required the creation of new elements within the NCAA system of governance for intercollegiate athletics. In somewhat oversimplified fashion, Table 1 outlines the system and the groups that contributed to its design and eventual operation. The group called Academic Consultants emerged from an action by the NCAA Board in April 1999 that approved a recommendation from the NCAA Management Council to form such a group. Work to form the Incentives and Disincentives Workgroup followed from work of the Division I Administrative Committee on September 5, 2002, that was in response to a Board directive to the 


\section{Table 1 Elements and Groups of Governance}

\begin{tabular}{ll}
\hline Group & Elements \\
\hline Academic consultants & New standards: initial eligibility, progress toward degree \\
Incentives and Disincen- & New metrics: Academic Progress Rate (APR), Graduation \\
tives Workgroup & Success Rate (GSR) \\
Committee on Academic & New consequences: penalties for unacceptable performance, \\
Performance & recognition for outstanding performance \\
\hline
\end{tabular}

Management Council. CAP was designated to administer the APP in legislation adopted by the NCAA Board in April 2004.

As is evident from the overview, the work on academic reform proceeded in overlapping segments. Each of these groups that contributed to the design of this system was comprised of representatives from the member schools of the NCAA and included a combination of faculty, university chief executive officers, campus athletic administrators, and conference officials, all supported by the NCAA staff.

\section{Initial Eligibility and Progress Toward Degree}

As Petr and McArdle (2012) and Paskus (2012) have outlined, Initial Eligibility is an NCAA term that defines the conditions that must be met for a prospective student-athlete coming out of high school to qualify for athletically related financial aid at the college level. Those who meet this standard are referred to as qualifiers. It is important to note that this is not a statement about admissibility to any member institution of the NCAA; that is an admission decision that is the province of the institution. Based on extensive data analysis, which Petr and McArdle (2012) and Paskus (2012) discuss at length, initial eligibility was defined by a sliding scale that expresses a tradeoff between test score (e.g., SAT) and core grade point average (CGPA) for a defined number of high school core courses. The sliding scale was placed at approximately one standard deviation below the national mean for all students. The graph below expresses this tradeoff, indicating that a low test score can be offset by a high CGPA, and likewise, a low CGPA can be offset by a high test score. A prospective student-athlete must have a CGPA of at least 2.0 and be above the sliding scale to qualify for athletically related financial aid at an NCAA member institution. The reasoning behind establishing this sliding scale was rooted in the portion of the NCAA Board's mandate to avoid disparate impact on ethnic minorities. Note that the relevant endpoints of the sliding scale are test score/CGPA combinations of (400/3.55) and (1010/2.00), as illustrated by the dotted lines in Figure 1.

We should note here that an entering student-athlete who met these criteria was eligible to practice, to receive financial aid, and to compete. In the section entitled "New Directions for the NCAA Academic Performance Program," we will review the new version of initial eligibility criteria that sets a higher standard for eligibility to compete.

The new Progress Toward Degree (PTD) standards were created to replace the former Continuing Eligibility requirements and were chosen to increase the likelihood that a student-athlete who met the new requirements would graduate within 
5 years. Examination of data revealed that the former requirements were allowing at least some student-athletes to maintain their athletic eligibility without resulting in steady progress toward graduation. A summary of the main elements of the new PTD requirements appears in Table 2. NCAA regulations permit a student-athlete to compete for 4 years within a 5-year window that starts with initial enrollment. If one assumes 120 semester hours as the requirement for graduation, the PTD conditions require a student-athlete to progress steadily toward graduation, completing essentially $20 \%$ of the total requirements for graduation in each of 5 years.

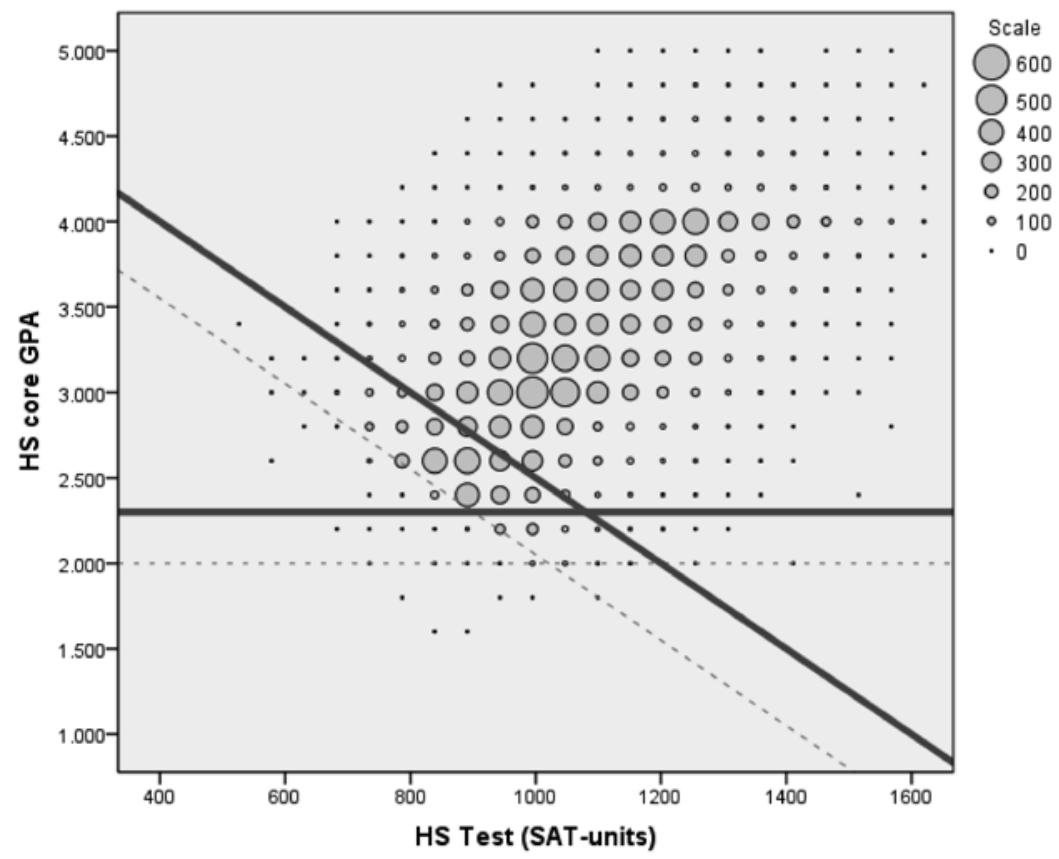

Figure 1 — Initial Eligibility Standards_Current and New for Fall 2015

\section{Table 2 Progress Toward Degree Standards}

\begin{tabular}{ll}
\hline $\begin{array}{l}\text { Year of } \\
\text { Enrollment }\end{array}$ & Requirement to Enter the Following Year \\
\hline First Year & $\begin{array}{l}\text { Completion of } 24 \text { semester hours of credit, and a GPA that is at or } \\
\text { above } 90 \% \text { of that required for graduation }\end{array}$ \\
Second Year & $\begin{array}{l}\text { Completion of } 40 \% \text { of the requirements for graduation, and a GPA } \\
\text { that is at or above } 95 \% \text { of that required for graduation }\end{array}$ \\
Third Year & $\begin{array}{l}\text { Completion of } 60 \% \text { of the requirements for graduation, and a GPA } \\
\text { that is at or above } 100 \% \text { of that required for graduation }\end{array}$ \\
Fourth Year & $\begin{array}{l}\text { Completion of } 80 \% \text { of the requirements for graduation, and a GPA } \\
\text { that is at or above } 100 \% \text { of that required for graduation }\end{array}$ \\
\hline
\end{tabular}




\section{New Metrics for Academic Performance}

The mandate from the NCAA Board grew out of a desire to improve graduation performance for student-athletes, particularly in high-profile sports. However, the way in which graduation had typically been measured presented two challenges for creating a system that would improve graduation performance.

Historically, graduation has been measured by what is called the Federal Graduation Rate (FGR) mandated by the U.S. Department of Education. A student, whether athlete or not, who enters for the first time as a full-time enrollee at an institution is recorded as a graduate or nongraduate for this metric at the conclusion of a 6-year period following initial full-time enrollment. The FGR, as reported publicly, is a 4-year average of the number of graduates from the institution of initial enrollment, divided by the number of initial full-time enrollments at the institution. Notice two important facts about this definition: (a) a student who transfers from the institution of initial enrollment, whether eligible to continue or not, is treated as a "graduation failure" for that institution; and (b) any student who transfers to an institution is not added to her or his cohort of initial enrollees at that institution and is therefore not accounted for in this metric.

In addition to the issue of transfers, any system that assigned penalties to an institution, program, or squad based on performance in the FGR (or any graduation metric) would be applying penalties to currently enrolled student-athletes for the lack of performance by student-athletes who had left the institution, whether as graduates or not. To create a system of performance measurement and consequences for the NCAA, metrics would be needed that addressed these issues. The Incentives and Disincentives Workgroup was the body that reviewed the statistical analyses and recommended the new metrics that became the measurement system at the core of what would become the NCAA APP.

The new metrics created were the Academic Progress Rate (APR) and the Graduation Success Rate (GSR). Since other authors in this issue have described these metrics, I provide only a brief summary here.

The APR was created to provide a "real-time" measurement of the academic performance of student-athletes on a given team. To create this metric, an extensive analysis of academic performance data for student-athletes was conducted to identify variables that would predict eventual graduation. This work revealed that retention and eligibility were strongly correlated with graduation. These variables became the basis for the APR, which is a 4-year moving average, computed for scholarship student-athletes on each squad that expresses the number of retention and eligibility points earned in a given year divided by the number of retention and eligibility points that were possible in the same given year. This ratio is then multiplied by 1,000 for ease of reporting and interpretation. In operation, each year of new data are incorporated into the 4-year moving average, and the oldest year of data are dropped from the calculation.

Because transfers are a reality in higher education and particularly for studentathletes, the Incentives and Disincentives Workgroup sought a graduation metric that would address this issue. The result was the GSR, a relatively straightforward modification of the FGR that can be described as follows. A student-athlete who leaves the institution of initial enrollment, but who was eligible to continue had he/she stayed at that institution, is removed from her or his cohort of initial enrollment. And, a student-athlete who transfers into an institution is added to 
the appropriate cohort of initial enrollment for purposes of measuring graduation performance.

The logic of these modifications is that a student who leaves an institution, but is eligible to continue, has met her or his academic responsibilities at that institution and should not be classified as a graduation failure there, but rather simply a nonevent, at least insofar as graduation is considered. However, a departing student-athlete who was not eligible to continue is still considered the responsibility of that institution and is treated as a nongraduate. Similarly, a student-athlete who transfers to an institution becomes the responsibility of that institution and is considered in determining the overall graduation performance of the squad that she or he joins. Using this new measurement of graduation includes almost 30,000 additional student-athletes (data for 2001-2004) being included in measurement of graduation performance in comparison with the FGR. In many cases, the GSR is higher than the FGR, but in a number of instances, particularly for squads that have a large number of transfer students, the GSR is lower than the FGR. Note that the GSR utilizes a 6-year time period for measurement, just as is the case for the FGR.

The combination of APR and GSR formed the measurement basis for the APP. Among the important early decisions in this design was the conclusion that the unit of measurement should be the squad and that all student-athletes receiving any amount of athletically related financial aid should be included in the measurement. With the completion of each year, new data are reported to the NCAA by member institutions, compiled by the NCAA staff, and reported, among other ways, through posting on the NCAA public web site. Interested individuals can learn the most recent APR and GSR results for any squad at any member institution at http://ncaa. org/wps/wcm/connect/public/NCAA/Academics/Division+I/.

\section{New Consequences (Penalties and Recognition)}

While the Incentives and Disincentives Workgroup did some preliminary work on a system of penalties for the APP, the CAP finalized the system, with approval by the Board of Directors. Initially, CAP proposed four years of APR data be gathered before any penalties were imposed and the committee proposed a four-level system of progressive penalties.

Setting of the threshold for team penalties was new territory for the NCAA, and one of the most important philosophical changes in the entire academic reform effort. First, penalties that might be applied to a squad needed to be based on a measure of performance the squad itself had produced (rather than some predecessor group). To accomplish this, the APR became the basis for assigning penalties because of its contemporary nature. The level of APR below which penalties would be assessed was then a complex discussion of the correlation between APR and graduation, the anticipated impact across member institutions of varying missions and resources, and the anticipated differential impact on squads in different sports. The CAP recommended 900 as the penalty threshold, noting that this level of APR corresponded to a FGR level of approximately 50\%. At the time, the GSR had not been implemented, so data on this metric were not yet available for consideration. The CAP also considered the effect of squad size: a football squad could have 85 student-athletes on financial aid, whereas a golf or tennis squad might have fewer than $10 \%$ of that number on aid. This difference was one reason for the recommendation that the APR be a 4-year rolling average, but even with that, CAP 
recommended use of what was called a squad-size adjustment that essentially gave small squads the benefit of the doubt in the early years.

Data analysis during the design stage of this system also revealed that lowresource and Historically Black Colleges and Universities (HBCUs) would likely be more heavily impacted than would other institutions. The response was implementation of a set of mission filters that would provide relief from penalties, particularly in the early years of operation of the APP. The filters were based on factors such as resource level of the institution, academic characteristics of the institution, comparison within a specific sport group, and demonstrated APR improvement over time.

The initial penalty structure recommended to the Board had four levels. Level One consisted of a warning letter, while Level Two entailed loss of playing or practice time. At Level Three, the team incurred loss of eligibility for postseason competition, such as bowl games or national championships. Finally, Level Four entailed restricted membership in the NCAA. This system obviously begins with a mild penalty, but it is progressive in severity.

While the Board accepted this overall penalty structure, the Board wanted impact from this new system without having to wait for accumulation of 4 years of data. In response, CAP recommended and the Board adopted what became known as the contemporaneous penalty. This penalty was to take effect based on three years of APR data, and it provided that any scholarship vacated by a student-athlete who was not eligible to continue could not be rewarded for any squad with an APR below 925. The originally proposed penalty structure became known as the historical penalties, and squads with APRs below 900 would be subject to those progressively more severe penalties once four years of APR data had been compiled. As is suggested by the two penalty levels, the contemporaneous penalty (taking effect for APR values below 925) was intended to be a "warning shot" in the first phase of implementation of the penalty structure. The historical penalties (taking effect for APR values below 900) were intended for instances of more problematic academic performance.

It was hoped that an incentive program could be developed to reward programs that were performing at very high levels. However, recognition of high levels of performance proved to be a complex topic for CAP. Early discussions explored possibilities for direct financial rewards for squads that performed well in the APR. Since any allocation of NCAA funds for this purpose would have been a reallocation from some other intended or planned use, these ideas did not win support from the membership. In the final analysis, the Committee decided to recognize publicly each year those squads with APRs in the top $10 \%$ of results for that sport. On the other hand, while it is possible to compute a program $A P R$, that is not done by the NCAA and is not encouraged. This emphasizes that the unit of measurement is the squad and that the consequences, whether penalties or recognition, are consistent with this concept.

This approach to academic reform was new territory for the NCAA. Previous efforts had been focused on initial eligibility and continuing eligibility requirements and measurement of graduation results via the FGR. This former approach provided neither in-process reporting of results nor mechanisms for identification of either poor or excellent performance, except to the extent that federal graduation data captured what happened to each cohort after it had completed its 6-year pipeline, again without adequately addressing transfers as noted above. This new system created measurement of progress for enrolled student-athletes and consequences that were intended to incentivize improvement where that was needed. 
Important guiding principles of the NCAA's approach to academic reform include:

- Utilizing data-based decisions for design. Each of the elements of the three-part system summarized above required careful consideration of issues that were inevitably complex because the NCAA membership and range of sports are complex. Accordingly, each step of the design work involved decisions that were based on the best data available to the NCAA.

- Learning and revising as appropriate based on experience during implementation. The desire to get a system into operation at the earliest practicable point was sometimes at odds with the objective to devise a system that was comprehensive and fair to all parties. These competing objectives led to the conscious decision to implement a good system, realizing that we could learn from early experience and adapt or refine the system based on the data obtained during early operating experience.

- Systematically evaluating after a suitable period of operating experience and revising as appropriate. Four years of data reporting would be required to compile the first 4-year averages of APR for all squads. Still more years would be required to gather the first experience with the initial penalty thresholds that had been set. With 2003-2004 being the first year of data reporting for the APR, the first entering cohort would complete its 6-year span for measurement of graduation results at the end of the 2008-2009 academic year. Finally, APR data through the 2008-2009 year would first be made public by the NCAA in the spring of 2010. These factors influenced scheduling of the first overall review of the APP. The review of the APP that occurred during the 2010-2011 year took advantage of the full range of data on results and the related experience with the APP to that point.

The next section contains a summary of implementation and experience during the first years of operation of the APP. The subsequent section presents results of the review of the APP and the new directions recommended by CAP and adopted by the NCAA Board in October 2011.

\section{Implementation}

A short chronology of the APP follows:

- 2003-2004 was the first year for which APR data were reported;

- 2005-2006 was the year following which the first 3-year average APRs were available for determination of contemporaneous penalties;

- 2006-2007 was the year following which the first 4-year average APRs were available for determination of historical penalties; hence, the first warning letters (Level 1 penalty) were issued based on data through 2006-2007;

- 2008-2009 was the year that completed the 6-year time window for the cohort that first enrolled in the fall of 2003 (the first year for which APR data were reported);

- 2009-2010 is the most recent year for which APR data were reported publicly; and 
- 2010-2011 is the most recently completed year. APR data for 2010-2011 have been submitted to the NCAA and will be reported publicly in the spring of 2012.

During the initial years of operation of the APP, three important adjustments were made to the way in which the APR is calculated. Each of these is summarized below:

- Delayed graduation point: With the APR based on the number of eligibility and retention points earned each semester (or quarter) by the scholarship student-athletes on a squad, an individual who leaves an institution without graduation results in the loss of at least a retention point, and possibly an eligibility point, as well. Recognizing that some of these individuals return to their institutions to complete their degrees, CAP instituted an adjustment to the APR that gave a squad credit for such a "delayed graduation." In essence this was simply allowing a squad to recover a retention point that had previously been lost. Recovery of a lost eligibility point was not possible through this mechanism. This adjustment was viewed as supporting the overall objective of the APP — namely, graduation.

- Professional departure adjustment: A number of sports obviously provide opportunities for professional careers, and numerous cases exist of departures before graduation to pursue these opportunities. After examination of the data related to this factor, CAP instituted an adjustment to the APR that gave a squad relief for what would otherwise be a lost retention point if a student-athlete left for a bona fide professional opportunity and was eligible to continue at the time of departure. Note that this adjustment was only permitted if the departing individual had met her or his academic responsibilities through the time of enrollment before departure. This includes the fact that to be eligible to continue, a student-athlete must be meeting the applicable PTD requirements.

- Eligible transfers: The original definition of the APR caused a squad to lose a retention point when a student-athlete transferred to another institution, even if at the time of the transfer the student-athlete was eligible to continue. This definition was adopted because of the high correlation between retention/eligibility and graduation. However, as noted above, the GSR, adopted as a new and more comprehensive measure of graduation, removed eligible transfers from the calculation of this graduation metric. The data showed that eligible transfers who had a cumulative GPA of at least 2.6 at the time of transfer were substantially more likely to graduate than were those who transferred with GPAs below 2.6. Based on this significant break in graduation performance, CAP adopted an adjustment to the APR that provided relief to a squad that experienced a transfer, provided the individual was eligible to continue and had a cumulative GPA of at least 2.6 (along with some additional minor conditions). This adjustment was adopted because it improved the consistency between the calculation of the APR and that of the GSR.

These adjustments, individually and in combination, had an effect on the distribution of APR data across the NCAA membership that can be summarized as follows: (a) the left tail of the distribution of APR scores moved up; (b) the mean and median values of the APR moved up; and (c) the variation in APR scores (typically summarized in the standard deviation) became smaller. Since the empirical changes indicated above mean shifts in the APR data, one could expect resulting 
changes in the number of squads above the penalty thresholds. This factor would become one of the issues requiring study in the future review planned for the APP.

The adjustments in calculation of the APR described above were generated primarily in response to feedback from within the NCAA. In addition, the APP was of interest to people and organizations outside of the NCAA. For example, the Knight Commission recommended that the harsher penalties, including loss of eligibility for postseason competition, should be imposed earlier in the penalty structure. In addition, in a 2009 speech to the NCAA Convention, United States Secretary of Education Arne Duncan recommended that men's basketball squads with graduation rates not be eligible for selection to the NCAA Tournament. While this penalty had been a part of the APP system from the beginning, it only occurred at Level Three of the original penalty structure. Secretary Duncan's recommendation was to make it a stand-alone penalty and to base it on graduation performance, rather than the APR. These proposals will be discussed in the following section.

The first years of APR data revealed that three men's sports were producing APR values noticeably lower than those of other sports. In response, the NCAA formed three successive groups-first the Baseball Academic Enhancement Group, then the (men's) Basketball Academic Enhancement Group, and third the Football Academic Work Group - to study these results, explore the contributing causes, and recommend legislation that would lead to improved performance. The lesson from this process was that each sport has its own characteristics that help to explain the academic performance observed in the specific sport. The Baseball group proposed a package of legislation that was adopted and implemented, and subsequent APR values have improved. Results from the Basketball and Football groups were recommended somewhat later and are still working their way through the NCAA legislative process. For example, one concept that emerged from the Basketball group, what has been called the Academic Year-in-Residence, is part of the package that will be described in the subsequent section.

In August 2011, NCAA President Mark Emmert convened a Presidential Retreat that included institutional Chief Executive Officers (presidents or chancellors) from each conference, as well as representatives from other relevant interest groups. That retreat identified academic integrity as one of the important themes for future work and noted that CAP was the appropriate working group to continue analysis and recommendations for action.

At this writing (spring 2012) the most recent publication of APR data by the NCAA occurred in the spring of 2011, meaning that data for the 2009-2010 year were the most recent data included in those reports. APR data for the 2010-2011 year have been submitted to the NCAA during the fall of 2011 and are now going through the annual cycle of corrections, adjustments, and waivers. Among other things, this means that two entering cohorts, those for fall 2003 and fall 2004, have completed the 6-year time window that is used for measuring graduation performance. This set the stage for CAP to conduct a comprehensive review of the APP, to consider all of the changes that had occurred, and to review all of the feedback and experience that had been accumulated during the 7 years of data reporting, penalty assignment, and public reporting. This work proceeded in collaboration and consultation with the Academic Cabinet - the two groups conducted a joint review of the requirements in initial eligibility. The proposals to the NCAA Board of Directors for modification that grew out of that review are summarized in the following section. 


\section{New Directions for the NCAA Academic Performance Program}

In its October 2011 meeting, the NCAA Board of Directors set a number of new directions for the NCAA APP that were a direct consequence of the data and analysis conducted by the NCAA CAP, supported by the NCAA Research Staff. Petr and McArdle (2012) and Paskus (2012) reviewed the results generated since the 2003-2004 first year of data reporting under this program. This included a summary of the modifications made in the calculation of the APR and the consequences in the aggregate data. As a result of analysis by CAP and parallel work by the NCAA Academic Cabinet, a set of new directions was recommended to the NCAA Board of Directors for consideration. This section will review those changes. They fall into four categories: (a) new initial eligibility standards; (b) new requirements for 2-year college transfers; (c) new requirements for eligibility for postseason competition; and (d) new penalty structure and penalty thresholds. It is important to note here that all of these issues were under consideration by CAP and the Academic Cabinet before the presidential retreat. Therefore, ideas for improvements in each of these areas were already quite ripe. Actions at the presidential retreat served more to confirm the commitment of the membership and condense the timeline for review, rather than to alter the overall policy direction that was already under discussion within these groups.

\section{New Initial Eligibility Standards}

Background. As has been noted earlier in this Colloquium, one topic that seems to be perpetually under discussion at the NCAA is the academic eligibility of freshmen student-athletes. Over the past few years, we have continued to hear that underprepared student-athletes are allowed to compete at Division I institutions. At the same time, data clearly indicate that many student-athletes who are close to our current minimum standards are academically successful. These realities make for challenging decision making when it comes to setting standards for financial aid, practice, and competition for Division I freshman student-athletes. Layer on significant institutional and demographic differences among our membership and student-athletes, and this issue becomes very complex.

Despite all of these difficulties, CAP and the Academic Cabinet forged ahead with efforts to alter our initial eligibility standards. The rules that we proposed represent something of a departure in philosophy from previous efforts in this area. Rather than starting with the presumption of eligibility for all student-athletes and imposing a floor for freshmen to receive financial aid, we began with a presumption of ineligibility for competition, with the ability for better-prepared students to become immediately eligible. While many more student-athletes may be impacted by the new standards, the penalty (losing the ability to compete) is not as harsh as in previous initial eligibility standards where access to higher education was at risk because rules were tied directly to receipt of athletics aid.

In the end, this constitutes a more nuanced approach to initial eligibility than we have taken in the past. Under the new standards, there remain students who have not prepared themselves sufficiently well in high school to provide them with the opportunity to receive a scholarship or compete at the collegiate level-these are the nonqualifiers. There are other students whom we believe 
have demonstrated sufficient academic ability to show us that they can handle the academic rigors of collegiate life at the same time as competing on the field of play-these are full qualifiers. Now, however, we have added a third group who are coming to us with some amount of risk from an academic perspective. Student-athletes who fall into this third group will still be able to receive athletically related financial aid and to practice, but they will not be allowed to compete or to travel with their athletics team. Instead, the student-athletes will spend an academic redshirt year to concentrate on their education before they are allowed to begin athletics competition.

It is the hope of the committee that this approach will continue to allow access to student-athletes who have reasonable chances of succeeding, but will assist those who are borderline students to get themselves appropriately integrated academically before adding the rigors of athletics competition to their lives at the college or university level.

Eligibility for Practice and Athletically Related Financial Aid. Require Prospective Student-Athletes (PSAs) to meet the current qualifier standard for eligibility for practice during the first regular term and receipt of athletically related financial aid during the first year. Second-semester (and second- and third-quarter) eligibility for practice requires successful completion of nine semester or eight quarter hours in the first regular academic term of enrollment.

What Is New. The requirement to complete nine semester (or eight quarter) hours in the first academic term to be eligible for practice in terms subsequent to the term of initial enrollment is new.

Eligibility to Compete During the First Year of Collegiate Enrollment. Require PSAs to satisfy three criteria: (a) achieve a higher core GPA/test score combination, what is referred to as the sliding scale (details follow below); (b) obtain a minimum core GPA of 2.3 in the 16 core courses currently required; and (c) meet additional core-course requirements (details follow below). The NCAA Board of Directors has set the new sliding scale at approximately one half of a standard deviation below the national student-body mean. This represents a move upward of the sliding scale of test score/CGPA combination from approximately one standard deviation below the national student mean, which had been the previous sliding scale for the combination of eligibility for practice, athletically related financial aid, and competition. The second requirement above simply raises the required minimum core GPA from 2.0 to 2.3.

To be eligible to compete in the first year of college enrollment, PSAs must successfully complete 10 core courses prior to the seventh semester (or equivalent) of high school; successfully complete seven of these 10 core courses in English, math, and natural/physical science; and use these core courses (and grades) in calculating the core GPA for purposes of meeting the sliding scale and GPA minimum. This imposes new requirements on both the timing and content of core courses taken. These new initial eligibility standards will be in effect for students entering any collegiate institution full time on or after August 1, 2015. As was done when the minimum number of core courses was increased from 14 to 16 , this effective date provides nearly four full academic years for adjustment to the new standards. 
In Figure 1, the horizontal solid line is set at a CGPA of 2.3 and the diagonal solid line is the new sliding scale of "tradeoffs" between CGPA and SAT score. A prospective student-athlete must be above both lines to qualify to participate in competition during the first term of enrollment.

This is the first instance of setting additional requirements for eligibility for competition, beyond the requirements for eligibility to practice and receive financial aid, during the first year of enrollment. This creates the possibility of a student-athlete who is eligible to practice and receive athletically related financial aid, but who is not eligible to compete during the first year of enrollment-what might be called an academic redshirt. The objective in this action is to continue to provide access to higher education for these individuals, but to remove the pressure and time requirements of competition and provide more time for academic work.

Based on current data, approximately $0.4 \%$ of current student-athletes would be ineligible for the combination of practice and aid. In addition, approximately $15.5 \%$ of current student-athletes would be ineligible for competition only.

\section{New Requirements for 2-Year College Transfer Students}

One of the clear findings from our academic data over the past several years is that transfer student-athletes from 2-year colleges perform less well academically than other student-athletes. This finding is an occasion when student-athletes actually perform somewhat differently than nonathlete students (e.g., 2-year college transfers) in the student body. We believe that this is because the reasons for studentathletes to attend 2-year colleges are fundamentally different (i.e., more likely to be due to academic deficiencies) than other students who attend 2-year colleges.

While we had clear evidence of this consistent underperformance among 2-year transfer student-athletes, we had no access to data regarding their academic backgrounds from the 2-year colleges until the NCAA began collecting information about the 2-year college academic preparation of these students, and those data then informed the recent policy changes that were adopted by the Association. Once we had collected the data, our analyses showed that the GPA at the 2-year college was the best predictor of academic success that we had available to us. We also saw that student-athletes who had completed work in a set of core-curriculum courses (e.g., English, math and science) were more likely to succeed at the 4-year institution. Finally, we observed that student-athletes who transferred with a significant number of physical education activity courses were less likely to be successful in our institutions than other 2-year college transfers. These findings contributed to the formulation the policy changes that are outlined below.

The NCAA Board of Directors adopted two legislative proposals (Numbers 2011-69 and 2011-70) that set additional requirements in order for students transferring from 2-year colleges to be eligible for competition. These requirements include: (a) increasing the minimum transferable GPA for eligibility for competition to 2.5 from the current 2.0; (b) permitting use of no more than two credit hours of physical education activity courses in all sports to meet requirements; and (c) requiring completion of three semesters or four quarters credit hours of transferable natural/physical science credit for nonqualifiers (individuals who did not meet the requirements of the sliding scale out of high school). 
The first requirement creates the possibility of a transfer student who is eligible to practice and receive financial aid, but not to compete- this would apply to an individual who has a transferable GPA of at least 2.0, but less than the 2.5 required for eligibility to compete. This parallels the academic redshirt status described above under initial eligibility.

These new transfer requirements will be effective for students initially enrolling full time in any college on or after August 1, 2012. A new waiver subcommittee of the NCAA Division I PTD Waivers Committee will be effective April 1, 2012, as a result of actions by the NCAA Board of Directors taken in connection with these new standards.

In addition to the actions summarized above, the NCAA Board of Directors allowed Proposal 2011-65 regarding establishing an academic year of readiness to continue in the normal legislative cycle. This could result in Board approval in either January or April of 2012.

\section{New Requirements for Access to Postseason Competition}

As Petr and McArdle (2012)and Paskus (2012) noted, over time there have been substantive changes made to the calculation of the APR score. While those changes emerged from recommendations from the membership and evaluation by the CAP, they did have an impact on what the APR score is and what it means. Because of that, for the past year CAP undertook a complete review of the APP program with a focus on understanding how the changes in APR may have impacted the number and type of teams being penalized. In that process, we learned that our estimated GSR for a given APR score had changed significantly from our original intent. Specifically, when we began this process, an APR of 900 was the score that best predicted a $50 \%$ GSR. After all of the changes to APR were put into place, the appropriate APR score to reflect a 50\% GSR was found to be between 925 and 930. This understanding led CAP to recommend (and the Board to adopt) a 930 as the new penalty threshold.

The preceding section contains a reference to Secretary's Duncan's recommendation regarding postseason eligibility. Other individuals and groups had raised a similar point. One specific recommendation was to base eligibility for postseason competition (bowls, tournaments, national championships) on graduation performance (e.g., the level of the GSR). A quick examination of that possibility reveals that it would impose the penalty on a squad that had nothing to do with producing the value of the GSR that earned the penalty. This is because, by definition of the GSR, individuals whose graduation performance is measured in the GSR have completed their 6-year time window for graduation and are no longer eligible for intercollegiate competition. In consequence, CAP sought a contemporaneous metric that could serve the same purpose.

After examination and deliberation the CAP recommended that the APR also be used to determine eligibility for postseason competition and also recommended that the same 930 threshold be used for this purpose. The Committee recommended, and the NCAA Board of Directors established, a 930 APR as a minimum academic standard for participation in postseason competition. Moreover, this is to be an annual determination of academic accountability. Previously, the possibility of postseason ineligibility was embedded in the multilevel penalty structure of the APP —at the 
third occasion. This action makes eligibility for postseason competition an annual and separate determination based on the most recently publicized 4-year average APR. Postseason competition includes all postseason events conducted after the last regular-season contest or end-of-conference tournament. Thus, it includes bowl games, the NCAA basketball tournament for men or women, the NIT, the WNIT, and so on. In sports in which individual competitors are identified for postseason competition, individuals on teams that fail to meet the team eligibility standard of 930 will not be eligible for postseason competition. Examples include swimming and track and field.

In taking this action, the NCAA Board of Directors also approved two "filters" that provide relief from the postseason eligibility requirements (but not relief from Levels One, Two, or Three penalties that are discussed later in this paper). The two relief filters are referred to as the Mission Filter and the Improvement Filter and are described below. A squad that falls below the threshold required for postseason competition can gain relief via the Mission Filter on the first occasion a team is below the penalty threshold. To qualify for relief via the Mission Filter, the institution must be in the bottom $15 \%$ of the resource distribution, as defined by the current CAP policy and the team's most recent 4-year GSR must be 50\% or higher. This

\section{Table 3 APR Benchmarks}

\begin{tabular}{|c|c|c|}
\hline $\begin{array}{l}\text { Postseason } \\
\text { Competition } \\
\text { Year }\end{array}$ & $\begin{array}{l}\text { Multiyear APR to Avoid } \\
\text { Ineligibility for Postseason }\end{array}$ & $\begin{array}{l}\text { Two Most Recent Years } \\
\text { Average APR to Avoid } \\
\text { Ineligibility for Postseason } \\
\text { (Improvement Filter) }\end{array}$ \\
\hline 2011-12 & $\begin{array}{l}\text { Status quo-current penalty struc- } \\
\text { ture and benchmarks apply }\end{array}$ & N/A \\
\hline $2012-13$ & $\begin{array}{c}\text { Four APR of } 900 \text { or higher } \\
\text { OR }\end{array}$ & $\begin{array}{c}\text { Two most recent years average } \\
\text { APR at or above } 930\end{array}$ \\
\hline 2013-14 & $\begin{array}{c}\text { Four-Year Apr of } 900 \text { or higher } \\
\text { OR }\end{array}$ & $\begin{array}{c}\text { Two most recent years average } \\
\text { APR at or above } 930\end{array}$ \\
\hline 2014-15 & $\begin{array}{l}\text { Four-Year APR of } 930 \text { or higher } \\
\text { OR }\end{array}$ & $\begin{array}{c}\text { Two most recent years average } \\
\text { APR at or above } 940\end{array}$ \\
\hline $\begin{array}{l}2015-16 \text { and } \\
\text { beyond }\end{array}$ & $\begin{array}{l}\text { Four-Year APR of } 930 \\
\text { *Improvement Filter applies the } \\
\text { second time and beyond a team is } \\
\text { subject to postseason ineligibility. } \\
\text { This filter requires the two most } \\
\text { recent years of APR must be at or } \\
\text { above } 950 \text {. }\end{array}$ & N/A \\
\hline
\end{tabular}

Note: The Mission Filter applies only the first time a team is subject to postseason ineligibility. In taking these actions regarding postseason competition, the NCAA Board of Directors also directed that each conference must adopt a written policy regarding teams subject to a postseason restriction. This written policy must address and clarify the conference's automatic qualification for postseason/ championship competition and revenue distribution. Each conference is permitted to develop its own policy, but a written policy will now be required. 
filter provides relief only from the postseason penalty and not from the Level One, Two, and Three penalties described subsequently. On the other hand, a squad that falls below the threshold required for postseason competition can gain relief via the Improvement Filter by showing meaningful improvement in its most recent years. Specifically, a team must have an average APR of 950 over the two most recent years to meet this test. This filter only applies to the second and subsequent times that a team is subject to postseason ineligibility. Appeals and waivers will be processed through the penalty structure process. APR benchmarks during the transitional phase for access to postseason competition are summarized in Table 3.

\section{New Penalty Structure: Three Levels}

Based on recommendations from CAP, the NCAA Board of Directors adopted a new, three-level penalty structure that will replace the current combination of contemporaneous and historical penalties. A summary of these changes is as follows. The current warning of a Level One penalty has been eliminated, as has the so-called contemporaneous penalty of nonrenewal of a vacated scholarship if the individual was not eligible to continue. Reduction in playing and practice time during the competition season (in-season) becomes a Level One penalty (where previously this penalty had been at Level Two). New Level Two penalties apply to nonchampionship seasons, spring football, or the championship season for sports that have no nonchampionship season. Finally, the changes create a menu of possible Level Three penalties to be administered by the Committee on Academic Performance.

A team subject to a Level One penalty would experience a reduction by 4 hours/one day of practice per week during the competition season (in-season). This results in a maximum of 16 hours/5 days of athletically related activity rather than the permissible 20 hours and 6 days in the absence of this penalty. The lost time must be replaced by academic activities.

A team subject to a Level Two penalty experiences the in-season reductions associated with a Level One penalty and also a reduction of 4 hours of practice per week out-of-season. In addition, if applicable, the nonchampionship season or spring football would be cancelled. Sports without nonchampionship seasons would experience a $10 \%$ reduction in contests and length of competition season. The NCAA Board of Directors is aware that other groups are considering the possibility of eliminating noncompetition seasons or reducing regular seasons. If these concepts progress to actions, CAP would revisit these penalty issues.

Teams that reach Level Three of the penalty structure would be subject to Level Three penalties repeatedly until the team APR improves. The menu of options available at this level includes financial aid penalties (any amount, any type); practice penalties (reduction of 4 hours/week and up); contest reductions (10\% up to full season); restricted and corresponding membership in the NCAA; coach-specific penalties, including game restrictions and recruiting restrictions; restricted access to practice for incoming student-athletes who fall below predetermined academic standards; or multiyear postseason competition ban. Under current policy a team that enters the existing multilevel penalty structure must achieve three consecutive years of penalty-free performance to recover to good standing.

APR benchmarks during the transitional phase for Level One, Two, and Three penalties are summarized in the Table 4. 


\section{Table 4 APR Benchmarks in Transitional Phase}

\begin{tabular}{|c|c|c|}
\hline $\begin{array}{l}\text { Championship/ } \\
\text { Postseason } \\
\text { Competition Year }\end{array}$ & $\begin{array}{l}\text { Multiyear APR to Avoid } \\
\text { Ineligibility for Level One, } \\
\text { Two, and Three Penalties }\end{array}$ & Improvement Filters \\
\hline 2011-2012 & Status Quo & Status Quo \\
\hline \multirow[t]{2}{*}{ 2012-2013 } & 4-Year APR of 900 or higher & Level One: None \\
\hline & OR Improvement & $\begin{array}{l}\text { Levels Two and Three: Two } \\
\text { most recent years APR average } \\
\text { of } 950 \text { or higher }\end{array}$ \\
\hline \multirow[t]{2}{*}{ 2013-2014 } & 4r-Year APR of 900 or higher & Level One: None \\
\hline & OR Improvement & $\begin{array}{l}\text { Levels Two and Three: Two } \\
\text { most recent years APR average } \\
\text { of } 950 \text { or higher }\end{array}$ \\
\hline \multirow{2}{*}{$\begin{array}{l}2014-2015 \text { and } \\
\text { beyond }\end{array}$} & 4-Year APR of 930 or higher & Level One: None \\
\hline & OR Improvement & $\begin{array}{l}\text { Levels Two and Three: Two } \\
\text { most recent years APR average } \\
\text { of } 950 \text { or higher }\end{array}$ \\
\hline
\end{tabular}

\section{Summary and Conclusion}

Now, let me offer some observations as we complete the first comprehensive review and embark on a new phase of the NCAA APP. The APP has been in effect for 8 years, seven of which (2003-2004 through 2009-2010) have been reported to the public on the established cycle for this process, and the most recent of which (2010-2011) will be reported in the spring of 2012. Progress in graduation performance has been made, in general, and in baseball, football, and men's basketball, in particular. However, men's basketball remains the sport with the lowest overall APR. Calculation and reporting of the APR and the GSR will continue as in recent years. Such adjustments in the calculation of the APR have made it advisable to adjust the penalty cut-score upward to 930 .

In addition, core-course requirements have been strengthened for prospective student-athletes, and initial eligibility requirements have been made more rigorous. The initial eligibility requirements for competition in the first year of enrollment have been strengthened, while the previous set of initial eligibility requirements will continue to provide access to higher education for student-athletes who will be eligible for athletically related financial aid and practice, but not competition during the first year of enrollment.

Now that several years of experience have been completed, it is also logical to consolidate the contemporaneous and historical penalties into a single, progressive penalty system. In addition, and after careful review, eligibility for postseason competition will become a separate, annual determination based on the 4-year APR, rather than a part of the progressive penalty system. Penalties have been modified to place loss of playing/practice time at the first level, and the third level of penalties has been converted to a menu of options to be administered by CAP. Finally, a carefully considered timetable for implementation of these changes has 
been defined that will provide time for adaptation at both the high school and college/university levels.

Division I of the NCAA has a complex and diverse membership. The NCAA Academic Performance Program has led to improvement in graduation performance, particularly in the sports that led to its creation, while also attempting to recognize and accommodate mission and resource differences that exist across Division I. The APP is entering a new phase, but it remains grounded in the principles that were summarized earlier in this paper. The Committee on Academic Performance will continue with data-based review and refinement of the APP.

\section{References}

Paskus, T. (2012). A summary and commentary on the quantitative results of current NCAA academic reforms. Journal of Intercollegiate Sport, 5, 41-53.

Petr, T.A., \& McArdle, J.J. (2012). Academic research and reform: A history of the empirical basis for NCAA academic policy. Journal of Intercollegiate Sport, 5, 27-41. 